This is an Accepted Manuscript of an article published by Elsevier in ISPRS Journal of Photogrammetry and Remote Sensing, available online on 28/06/2014:

http://www.sciencedirect.com/science/article/pii/S0924271614001518

To cite this article: Lei Fan, William Powrie, Joel Smethurst, Peter M. Atkinson and Herbert Einstein (2014): The effect of short ground vegetation on terrestrial laser scans at a local scale, ISPRS Journal of Photogrammetry and Remote Sensing, 95, 42-52 (doi:10.1016/j.isprsjprs.2014.06.003). 


\title{
The effect of short ground vegetation on terrestrial laser scans at a local scale
}

\author{
Lei Fan ${ }^{\mathrm{a}}$, William Powrie ${ }^{\mathrm{a}}$, Joel Smethurst ${ }^{\mathrm{a}}$, Peter M. Atkinson ${ }^{\mathrm{b}}$ and Herbert Einstein ${ }^{\mathrm{c}}$ \\ ${ }^{a}$ Faculty of Engineering and the Environment, University of Southampton, University Road, \\ Southampton, SO17 1BJ, UK. (Lei.Fan@soton.ac.uk; W.Powrie@soton.ac.uk; \\ J.A.Smethurst@soton.ac.uk) \\ ${ }^{\mathrm{b}}$ Geography and Environment, University of Southampton, University Road, Southampton, SO17 \\ 1BJ, UK. (P.M.Atkinson@soton.ac.uk) \\ ${ }^{\mathrm{c}}$ Department of Civil and Environmental Engineering, Massachusetts Institute of Technology, 77 \\ Massachusetts Avenue, Cambridge, MA, 02139, US. (einstein@mit.edu)
}

Corresponding author: Lei Fan; lei.fan@soton.ac.uk

\begin{abstract}
Terrestrial laser scanning (TLS) can record a large amount of accurate topographical information with a high spatial accuracy over a relatively short period of time. These features suggest it is a useful tool for topographical survey and surface deformation detection. However, the use of TLS to survey a terrain surface is still challenging in the presence of dense ground vegetation. The bare ground surface may not be illuminated due to signal occlusion caused by vegetation. This paper investigates vegetation-induced elevation error in TLS surveys at a local scale and its spatial pattern. An open, relatively flat area vegetated with dense grass was surveyed repeatedly under several scan conditions. A total station was used to establish an accurate representation of the bare ground surface. Localhighest-point and local-lowest-point filters were applied to the point clouds acquired for deriving vegetation height and vegetation-induced elevation error, respectively. The effects of various factors (for example, vegetation height, edge effects, incidence angle, scan resolution and location) on the error caused by vegetation are discussed. The results are of use in the planning and interpretation of TLS surveys of vegetated areas.
\end{abstract}

Keywords: Terrestrial Laser Scanning (TLS); Vegetation; Error; DEM/DTM; Point Could; Resolution

\section{Introduction}

Recent years have witnessed the increasing use of terrestrial laser scanning (TLS) for various applications, such as topographical survey (Gallay et al., 2013), geology (Buckley et al., 2008) and surface deformation monitoring (Vezočnik et al., 2009; Schürch et al., 2011). However, the use of TLS for some applications may be limited by specific environmental factors, such as the presence of vegetation. Laser scanning techniques (in particular Airborne Laser Scanning (ALS)) have been used to capture the characteristics of vegetation such as its structure, height, density and tree canopy characteristics (Lim et al., 2003; Hall et al., 2005; Webster et al., 2006). It is widely recognized that the low oblique angle of transmitted signals from TLS means that it is much more prone to occlusion by vegetation and other objects (such as fencing), which can obstruct TLS signals, than ALS. In vegetated areas, TLS signals may be reflected back to the instrument by vegetation. It is unknown how significantly vegetation affects TLS measurements and the surface changes derived from repeated TLS surveys. 
Several researchers (Pfeifer et al., 2001, 2003, 2004; Töyrä et al., 2003; Hodgson and Bresnahan, 2004; Hopkinson et al., 2005) have attempted to evaluate the vegetation-induced errors associated with ALS. Hopkinson et al. (2005) used data from a Boreal wetland environment to estimate land cover (or vegetation class) dependent elevation errors. Real-time differential GPS was used to provide reference elevation data for comparison with ALS data. Pfeifer et al. (2004) discussed the influence of vegetation on ALS elevation data and possible corrective approaches.

Few studies have been carried out to investigate the effects of vegetation on TLS surveys. Coveney and Fotheringham (2011) attempted to quantify the vegetation-induced elevation error for an open, large and relatively flat coastal saltmarsh area, fully covered by dense and short vegetation. They found that the elevation error caused solely by vegetation was about five times the arithmetic sum of all other survey-related errors (assuming none of these offset each other). Guarnieri et al. (2009) carried out research into the retrieval of small-relief marsh morphology from TLS, and found that the vegetation-induced uncertainty was in the order of a few centimetres. Day et al. (2013) investigated the use of TLS for measuring bluff erosion and discussed the effect of ground vegetation in this application. Pirotti et al. (2013) investigated the use of a multi-return terrestrial laser scanner in measuring vegetated ground, and proposed a work-flow for identifying ground points and deriving digital terrain and surface models. These studies were based on relatively large areas and investigated the overall vegetation-induced error.

When TLS is employed to survey a large area, the final survey data are essentially a combination of many sub-scans. In general, TLS is more commonly used to survey or monitor a local and relatively small area (e.g. a slope), because many laser scanners have a relatively short useful scan range. Therefore, it is appropriate to carry out a more detailed investigation of the elevation error caused by ground vegetation and its spatial pattern at a local scale, and the associated contributing factors.

Previous research has often focused on the assessment of vegetation-induced elevation error in data acquired from a single survey campaign. For deformation detection over a period of time, multitemporal data are required. As vegetation-induced error exists in each set of successive survey data, comparison between two sequential datasets may cancel out a proportion of it, resulting in a reduced elevation error. The extent of this reduction is not well understood.

The aim of this paper is to investigate the effect of short ground vegetation on elevation data from TLS surveys. Several parameters that might affect the vegetation-induced error are investigated, including edge effects, vegetation height, scan resolution, incidence angle and scan distance. The effects of vegetation on the surface deformations derived from repeat TLS surveys are also discussed. The scanner used was a single-return Leica ScanStation C10. The research was undertaken in the context of a local vegetated area.

\section{Study site and data}

\subsection{Site}

For ease of access and mobility, a fairly large area of grass was selected for the experiment, located on the campus of the University of Southampton. The characteristics of the grass were similar to those on some engineered slopes in the UK. The site layout and the detail of the grass are shown in Fig. 1. The site could be considered to be like a lawn. The grass was green, quite dense and upright, and had moderate tolerance for foot traffic. It was mown regularly, and at the time the experiment was carried out its height generally varied from $70 \mathrm{~mm}$ to $140 \mathrm{~mm}$ although some individual grass leaves were shorter than $70 \mathrm{~mm}$ or longer than $140 \mathrm{~mm}$ locally. 


\subsection{TLS survey}

The area was scanned using the Leica ScanStation C10 from two different stations (Stations 1 and 2). Three Leica targets were placed in the area to enable registration of the survey data. The scanner was first placed at Station 1 from where the whole grassland was scanned with a coarse spatial resolution (Fig. 2(a)). Further three scans were then carried out for the subarea with scan resolutions fine, coarse and fine. During this process, the scanner stayed at the same location (Station 1) and height, and in the same orientation. All the resolutions used in this study referred to a scan distance of $100 \mathrm{~m}$. They are defined by Leica and are available in the scan menu (horizontal and vertical spacing at $100 \mathrm{~m}: 0.2 \mathrm{~m} \times$ $0.2 \mathrm{~m}$ for low (coarse) resolution; $0.05 \mathrm{~m} \times 0.05 \mathrm{~m}$ for high (fine) resolution) (Leica Geosystems, 2012a). Once the surveys from Station 1 had been completed, the scanner was moved to Station 2 from where the whole area was scanned with coarse and fine scan resolutions. The Leica targets remained in place for data registration and were scanned from both stations. The point clouds acquired in sequence and the associated abbreviations are listed in the following:

S1L1: The first coarse (low)-resolution scan from Station 1 (the whole area)

S1H1: The first fine (high)-resolution scan from Station 1 (the sub-area only)

S1L2: The second coarse (low)-resolution scan from Station 1 (the sub-area only)

S1H2: The second fine (high)-resolution scan from Station 1 (the sub-area only)

S2L: $\quad$ The coarse (low)-resolution scan from Station 2 (the whole area)

S2H: The fine (high)-resolution scan from Station 2 (the sub-area only)

\subsection{Bare ground survey}

An accurate Leica total station (range accuracy $1 \mathrm{~mm}$; angle accuracy 1 second) was used to establish the bare ground surface, measuring a reflective target attached to a pole. The height of the target was known. The pole was held vertically with the aid of a mini-tripod equipped with a bubble level. Care was also taken to ensure that the bottom of the pole just touched the bare ground surface. The Leica targets placed for survey data registration were measured first. This enabled the point clouds to be transformed into the coordinate system of the total station measurements. The target on the vertical pole followed approximately a regular grid and 481 ground points were measured (Fig. 2(b)).

An existing manhole cover (shown in Fig. 2(a)) was also surveyed with the scanner and the total station. The survey data associated with this manhole cover were later used to show that the errors from other sources were minimal.

\subsection{Edge effects}

As beams emitted by laser scanners have a small amount of divergence, the laser beam hits a surface across a footprint rather than at a point. At discontinuous edges, the footprint is divided into parts and multi-returns may be received by the scanner. Several researchers (Boehler et al., 2003; Lichti et al., 2005; Tang et al., 2009; Centeno et al., 2010) have investigated edge effects or the spot size of laser beams for a number of scanners.

The top surface of vegetated ground is not continuous as gaps are present between individual grass leaves. When a laser beam hits grass, it may be reflected by a grass leaf if the width of an individual leaf is larger than the spot size of the laser beam. Equally, it may interact with the edges of grass leaves, in which case edge effects occur. Since the width of an individual grass leaf is usually small, edge effects are likely to occur frequently in a scan of a grass-vegetated area. If a laser beam hits the edge of a grass leaf, a proportion of it may continue to travel to another surface, which could 
be another leaf, the bare ground surface or again an edge of another leaf. The footprint of the remaining signal on the subsequent surface is normally further from the scanner and at a different elevation from that on the surface edge illuminated first. This implies that many of the data points in a point cloud do not represent the actual positions of grass but lie somewhere between two or several grass leaves (or between grass leaves and the bare ground) that interact with a single laser beam.

The spot size for the ScanStation C10 is $4.5 \mathrm{~mm}$ (FWHH-based) within a distance of $50 \mathrm{~m}$ (Leica Geosystems, 2012b). The spot size also depends on the angle of incidence of the beam relative to the normal to the surface being illuminated (Soudarissanane et al., 2011). To understand how the ScanStation C10 calculates the distance when edge effects occur, a simple experiment similar to Centeno et al. (2010) was carried out, in which two white plates at a distance of $5 \mathrm{~m}$ from the scanner were scanned head on. The white plates were separated by a distance of $15 \mathrm{~mm}$ (Fig. 3(a)). The point cloud (Fig. 3(b)) obtained manifests a transition zone at the discontinuous edges, containing a trail of points. These point locations in the transition zone do not exist on the real surface.

The continuous transition zone suggests that the ScanStation C10 calculates distances based on the weighted average of the distances of the two surfaces from the scanner, with the weight likely depending on the size of the footprint on each surface. A larger proportion of the spot size on the front surface and a smaller proportion on the back surface resulted in a data point that was closer to the front surface. In this case, the surface materials of the front and back surfaces and hence the surface reflectance were the same. If the reflectivity were different, the distance calculated by the scanner might also depend on the surface reflectance. In other words, the size of the footprint on each surface and their reflectance may combine to determine the weights used for range calculation in the transition zone.

In the first experiment, the separation between the two surfaces was small $(15 \mathrm{~mm})$. To determine how edge effects change when the separation of the two discontinuous surfaces increases, a second experiment was carried out. In this second experiment, the front surface was fixed in place while the back surface was moved away from the front one in steps of $50 \mathrm{~mm}$. The results in Fig. 4 (only a few key separations are shown) show that edge effects were still apparent when the separation was increased to $150 \mathrm{~mm}$. However, when the separation was increased to $250 \mathrm{~mm}$ the artificial points existed only in a proportion of the transition zone close to the front surface. The proportion decreased with increasing separations between the two surfaces. At a separation of $900 \mathrm{~mm}$, the edge effects had effectively vanished although a few scattered noisy points close to the edge of the front surface were observed. The variation of the length of edge effects with the separation between the two surfaces is also summarised in Fig. 4.

\section{Data processing}

Data registration (the point clouds from Stations 1 and 2 were registered to the coordinate system of the total station) and initial data processing such as data selection were carried out using the Leica Cyclone $^{\circledR}$ software. Data filtering was implemented in MATLAB ${ }^{\circledR}$, and the post-filtering data exported to $\operatorname{ArcMap}^{\circledR}$ for surface generation, comparison and visualisation.

\subsection{Bare ground surface}

Based on the bare ground points surveyed, the bare ground surface (Fig. 5) was generated using the natural neighbour interpolation method developed by Sibson (1981). This method provided a smoother approximation than a linear interpolation and did not require any input parameters apart from the data points. A more complicated interpolation method such as kriging was not necessary for 
this study since the data density was relatively high and the ground surface was flat. For consistency, the natural neighbour interpolation was used for all the surfaces generated in this study.

\subsection{Methods to reduce vegetation noise}

Ground vegetation results in noisy data if the information desired is the bare ground surface. In this circumstance, the noise needs to be eliminated or reduced. The most direct solution is to remove the grass physically before the laser scans take place. However, this may not always be feasible, especially for a large area. Thus filtering methods need to be considered instead.

The literature reports a variety of filtering methods for different applications. In this paper, a simple local-lowest-point filter was used. A second method, based on the intensity of scan points, is also discussed as being potentially useful in certain cases. As the grass at the study site was dense, the TLS data are likely to represent the vegetation only. Therefore, the second method was not considered suitable for this study.

\subsubsection{Local lowest point}

The local-lowest-point filter approach has been used by several researchers to remove or minimize vegetation-induced error (Latypov 2002; Guarnieri et al. 2009; Wang et al. 2009; Coveney and Fotheringham 2011). In this method, a window (usually a square) of a given side length is first defined. The window moves stepwise to select a series of local minimum elevation points. This method works well when the terrain is flat with little variation in elevation. For inclined terrain such as an engineered slope, this method may be less useful since spatial changes in elevation will influence the selection of the local lowest points. In the case of rough hilly terrain, this method can also result in the top of convex-shaped surfaces being removed. Two simple solutions for an inclined surface would be: (i) to detrend the surface and then apply the local-lowest-point method, or (ii) to create a series of local fitting surfaces and choose the point furthest below the fitting surface as the lowest point. Alternatively, other types of filter such as linear prediction (Kraus and Pfeifer, 1998; Pfeifer, et al., 2001) and TIN densification (Axelsson, 1999, 2000) may be considered.

For a survey dataset already obtained, the local lowest points represent the best results that can be achieved. The only parameter affecting the selection of the lowest points is the size of the moving window. There are no standards for determining the size of the search window. In general, a larger search window is likely to capture a point closer to the bare ground, and hence reduces the overall vegetation-induced elevation error. However, a larger window will lead to data of coarser spatial resolution.

In this study, the window size was fixed to $60 \mathrm{~mm}$ by $60 \mathrm{~mm}$, based on the following considerations: (i) the search window should preserve the systematic elevation error caused by the vegetation and its spatial characteristics; (ii) the vegetation height estimated by local highest points should match approximately the actual grass heights (the moving-window approach was also used to choose local highest points for the estimation of local vegetation height.).

The step size of the window movement was also $60 \mathrm{~mm}$, leading to a grid of non-overlapping cells each $60 \mathrm{~mm}$ by $60 \mathrm{~mm}$. In each grid cell, one local lowest point and one local highest point were selected. The use of the same window size over the whole survey area can cause a relative bias if scan data densities vary spatially. This bias can be used to assess the dependence of vegetation error on data density. 


\subsubsection{Intensity method}

The laser emitted by the ScanStation C10 is a green visible pulse of wavelength $532 \mathrm{~nm}$ (Leica Geosystems, 2012b). In addition to the $x y z$ coordinates, the intensity of each scan point is also recorded, which represents the power density of the reflected laser light. The intensity depends on the surface reflectance; different surface materials in a scan scene may give different intensities. Such a distinction in intensity can be considered for data classification or filtering. In the context of vegetated ground, the intensity of grass is different from that of soils for the same scan conditions and survey geometry. However, the intensity also depends on other parameters such as scan distance and angle of incidence of the beam relative to the normal to the surface being illuminated. Several researchers (Kaasalainen et al. 2005 and 2009; Hofle and Pfeifer 2007; Pfeifer et al. 2007; Jutzi and Gross 2009; Errington et al. 2011) have investigated the effects of surface reflectance, incidence angle and scan distance on intensity and tried to find relations between these parameters and intensity.

However, such relations are unlikely to hold for real scans since many parameters combine to determine the actual intensity. In the context of vegetated ground surfaces, the intensity may also be influenced by edge effects. Nield et al. (2011) found that the moisture content of soils affected the intensity of the survey data acquired in a beach environment. Thus it is difficult to identify a general algorithm that can identify different types of materials based solely on the intensity recorded by the TLS. Nevertheless, the intensity data may aid in the classification of different objects in a particular case. For example, Guarnieri et al. (2009) reported on the use of intensity to classify objects presented in a marsh land, including vegetation, bare soil and water.

\subsection{Vegetation surface, height and error}

To avoid confusion, some of the terms used in the rest of this paper are defined in this section, with the aid of the illustration shown in Fig. 6.

The lower/upper bounds for the vegetation surface: A series of local lowest/highest points were selected using the moving window described in Section 3.2.1. Based on these points, the lower/upper bounds for the vegetation surface were created using natural neighbour interpolation.

Vegetation error: The vegetation error was defined as the elevation difference between the postfiltering point cloud and the bare ground. To show its spatial characteristics, the lower bound for the vegetation surface was used in this paper. Hence the vegetation error was represented by the elevation difference between the lower bound for the vegetation surface and the bare ground surface. Note that the term vegetation error is used loosely to refer to the elevation error caused by ground vegetation in the following discussion.

Vegetation height: It was assumed that the local highest points gave a reasonable representation of the top surface of the vegetation. The vegetation height was represented by the difference between the upper bound for the vegetation surface and the bare ground surface.

Penetration depth: defined as the elevation difference between the upper and lower bounds for the vegetation surface.

The process from the selection of local lowest and highest points to the creation of lower and upper bounds for the vegetation surface is illustrated in Fig. 7. Taking the S1H1 point cloud, for example, the number of data points (Fig. 7(a)) was 0.76 million. The original point cloud was thinned using a $60 \mathrm{~mm}$ by $60 \mathrm{~mm}$ search window. The post-filtering point cloud (Fig. 7(b)) had 8348 data points. The lower-bound of the vegetation surface is shown in Fig. 7(c). 


\section{Results}

\subsection{Total station measurement accuracy}

The total station had a very high range and angular accuracy. The pole supporting the target was held vertically with the aid of a mini-tripod, and the ground points were within $15 \mathrm{~m}$ of the total station. Thus the accuracy of individual measurements was expected to be better than $+/-3 \mathrm{~mm}$. The interpolation error of the bare ground surface was also small because the ground was relatively flat and a dense sample of ground points was acquired. Thus the ground surface was an accurate representation of the actual terrain surface.

\subsection{Registration error}

All of the survey data were registered to the coordinate system of the total station. Registration was carried out using Cyclone ${ }^{\circledR}$ and the maximum registration error reported was approximately $+/-2 \mathrm{~mm}$. An adjacent building was also recorded by the scanner from different scan locations. The scan data representing the building facade confirmed a registration accuracy of better than $+/-2 \mathrm{~mm}$. As this is very small, it is not considered separately in the following discussion on the vegetation error.

\subsection{Vegetation error and factors influencing it}

The vegetation height and error maps for the S1H1 point cloud are shown in Fig. 8 (a) and (b), respectively. The vegetation height and error at the manhole cover were both about $+/-2 \sim 3 \mathrm{~mm}$. This suggests that the measurement (total station and laser scanner) and registration errors had small effects on the assessment of the vegetation error.

There is a large positive correlation between the two datasets (Fig. 8 (a) and (b)) in most areas. In general, greater vegetation errors occurred where the grass was longer. However, the vegetation error was relatively small for the area close to Station 1 despite relatively long grass being present. Two main factors might have caused this. One is the density of scan points, which tended to decrease with the scan distance. The other is the incidence angle (the angle formed by the laser beam and the normal to the surface being illuminated). Ground visibility decreased as the incidence angle increased. Smaller incidence angles for closer ground areas meant that it was easier for laser beams to penetrate through the grass and reach a lower level.

To confirm these points, the spatial data shown in Fig. 8 are visualised differently in Fig. 9. In Fig. 9(a), the vegetation error is plotted against the vegetation height, giving a line of least-squares fit of having a slope of 0.65 . This value can change with the size of the search window adopted. Interestingly, the fitted line passes through the origin, i.e. there is no vegetation error if the vegetation height is zero. Hence the average vegetation error was about $65 \%$ of the vegetation height. This linear relation indicates that the growth of grass would increase the vegetation error in TLS survey data. The variation of the data from the fitted lines in Fig. 9(a) was relatively large. This was because several parameters combined to influence the vegetation error, such as incidence angle, data density and edge effects.

To investigate how the vegetation error varies with the scan distance, data points representing vegetation heights between $0.135 \mathrm{~m}$ and $0.15 \mathrm{~m}$ were selected. The horizontal distances between the individual data points selected and the scanner were then calculated. The variation in vegetation error with scan distance (and incidence angle) is shown in Fig. 9(b). For grass of similar heights $(0.135 \mathrm{~m} \sim$ $0.15 \mathrm{~m}$ ), the vegetation error increased gradually with scan distance and then plateaued. The rate of change in incidence angle decreased quickly and its influence vanished for distant areas (Fig. 9(b)). The data density, which decreased with the scan distance, was also a major contributing factor. The 
scatter in the data in Fig. 9(b) was likely due to the variation of the actual grass height within each individual search window.

Fig. 6 shows that the penetration depth is equivalent to the difference between the estimated grass height and vegetation error. Based on the linear relation shown in Fig. 9(a), the average penetration depth was about $35 \%(=1-0.65)$ of the grass height. Its dependence on the vegetation height was most likely due to the variation of vegetation density along its depth. At the study site, it was observed that short grass was generally denser than longer grass. However, it is important to appreciate that the penetration depth was affected by other factors such as the incidence angle. Hence it varied spatially for vegetation of the same height but with different incidence angles.

\subsection{Other factors affecting vegetation error}

The vegetation error reported in Section 4.3 was based on a single scan $(\mathrm{S} 1 \mathrm{H} 1)$. The vegetation error derived from the survey data obtained in another scan situation may be different. The differences and associated contributing factors are investigated in this section.

The S1H1 point cloud served as the reference TLS dataset. The point cloud obtained at another scan situation was compared with the reference one to produce the relative vegetation error, which was used for the following discussion. An advantage of using the relative error is that it shows the extent to which the vegetation effect may be reduced in surface deformations derived from repeat surveys of the same area. As the same bare ground surface was used to derive the vegetation error, the relative vegetation error is equivalent to the difference between the lower bounds for the vegetation surface of the two TLS datasets compared.

\subsubsection{Repeatability}

Although many terrestrial laser scanners record data points in a regular pattern (defined by horizontal and vertical scan resolutions), there are random elements in the laser scanning process. The selection of initial scan angles may be different in repeat scans. There are also random errors in the direction of a laser beam. In addition, the grass can sway in the wind and hence edge effects may vary from one scan to another. In a vegetated environment, these random uncertainties combine to affect the repeatability.

The lower bound for the vegetation surface was derived for the point clouds S1H1 and S1H2. These lower bounds were then compared and the difference is shown in Fig. 10(a). The result for two successive coarse-resolution scans (S1L1 and S1L2) is shown in Fig. 10(b).

There is no systematic difference in either case. The standard deviation of the differences for repeat fine-resolution scans was $4 \mathrm{~mm}$. In addition to the random uncertainties described earlier, measurement errors could also contribute to this difference. Since this difference was not great, it is reasonable to argue that repeat fine-resolution scans are not sensitive to random errors. The difference for repeat coarse-resolution scans was $+/-8 \mathrm{~mm}$ (at $1 \sigma$ ). Thus random uncertainties have a greater influence on repeatability for coarse-resolution surveys.

\subsubsection{Different scan resolutions}

Fig. 11 shows the difference in the relative vegetation error between the point clouds S1H1 and S1L1. The distribution of the differences shows a bias of about $11 \mathrm{~mm}$. This suggests that in general a finer scan resolution is likely to reduce the vegetation error. However, the point cloud of the coarse resolution had smaller vegetation errors at a limited number of locations. The magnitude of vegetation error depends largely on the depth that the laser signals can travel to. The actual depth reached by an 
individual laser beam does not depend on the scan resolution. However, a finer resolution produces more laser beams within a given area. This will increase the overall chances of laser beams reaching a lower depth.

The reduction in vegetation error using a finer scan resolution was less obvious for the area adjacent to Station 1. In this case, it is likely that the density of the grass played a major role. As the grass was quite dense, the space between grass blades was limited. Meanwhile, the point density for a coarse-resolution scan was also relatively high in the area adjacent to the scanner. There might be a limit beyond which further increases in scan resolution would not reduce the vegetation error. This was because the edge-effect weighting (Section 2.4) was limited by the spot size relative to the gap between grass leaves.

\subsubsection{Different scan locations}

The same area was scanned from two different locations (Station 1 and Station 2), both with fine scan resolution. The relative vegetation error is illustrated in Fig. 12 and its distribution shows a wide dispersion. The bias was $5 \mathrm{~mm}$ and the standard deviation was $15 \mathrm{~mm}$. In addition to the random errors discussed in Section 4.4.1, several factors led to these differences. The point densities and incidence angles over the scan area were different because the scan distances from Stations 1 and 2 were generally different. Variations in vegetation characteristics (e.g. leaf orientation) from different view directions may have also contributed. For the small area close to Station 1, the vegetation error in $\mathrm{S} 1 \mathrm{H} 1$ was smaller than that in $\mathrm{S} 2 \mathrm{H}$, because of the higher point density and smaller incidence angle for this area. The positive and negative differences were about the same in the distribution plot (Fig. 12). This suggests that scanning the same area in multiple directions may reduce the overall vegetation error.

\section{Discussion}

The study results confirm that lower incidence angle can reduce vegetation error. This reduction is quite effective for the dense vegetation in this case study. Hence it would be better to place a scanner at a lower level to scan an area of a vegetated slope at a higher level. In practice, however, it could be difficult to identify a favourable scan direction along which the vegetation error is the smallest. Therefore, a combination of scans of the same area in different directions could potentially reduce the overall vegetation error.

The average vegetation error in the TLS data representing a densely vegetated area is reasonably large. In this case study, it was about $65 \%$ of vegetation height. Digital elevation models created from these TLS data may not be fit for purpose for some applications, depending on the requirements of accuracy. In cases where a high accuracy is essential and the sites to be surveyed are relatively small (e.g. engineered slopes), it would be better to remove vegetation before scans are carried out.

For surface deformation detection, repeat scans at a certain time interval are needed. A vegetation error is present in each individual scan and a proportion of it can be cancelled out when multi-temporal TLS data are compared. The results in this case study suggest that repeatedly surveying a vegetated area from the same multiple locations and with the same scan parameters (fine resolution is preferred) is likely to reduce the vegetation error in the measured surface deformations. Another problem for monitoring the vegetated terrain surfaces is the growth or die back of vegetation over time, which can cause a systematic elevation error in surface deformations. This error can be estimated if the relation between vegetation error and height for a particular type of grass can be established. 
A larger search window generally leads to lower data points and hence reduces the overall vegetation error. However, the price of using a larger search window is the loss of point density in the final data set. The spatial characteristics of the terrain surface may also disappear. These factors have to be balanced when a search window size is selected.

The average penetration depth was about $35 \%$ of the grass height. A potential use of this relation is to estimate the grass height from the penetration depth, defined simply as the difference between the upper and lower bounds for the vegetation surface. The grass heights estimated and the upper bound for the vegetation surface could then be used to infer the bare ground surface. However, it is important to appreciate that this value (35\%) represents an average level of penetration. The penetration depth varied spatially, mainly depending on grass characteristics (including, height), incidence angles and scan resolutions (or data densities). To estimate the bare ground surface more accurately, the biases caused by incidence angles and data densities must be removed. An attempt was made to estimate the elevation of the terrain in this study. The prediction accuracy (i.e. the residuals from a comparison between the estimated elevation and the ground reference) was about $+/-13 \mathrm{~mm}$ (at $1 \sigma$ ).

A second experiment was carried out at a site where the grass was shorter (mostly $35 \mathrm{~mm}-80$ $\mathrm{mm}$ ) and slightly less dense. The experimental methods were similar to those stated in Section 2 . The selection of local lowest and highest points was based on a search window size of $60 \mathrm{~mm}$ by $60 \mathrm{~mm}$. The results showed similar behaviour to that discussed in Section 4.3. However, the average vegetation error was found to be approximately $60 \%$ of the grass height, slightly smaller than that $(65 \%)$ for the first site. The difference is reasonable and can be seen as some evidence of generalizability, as the grass at the two sites had different characteristics. The results of the two experiments reported in this paper suggest that the relation between vegetation error and grass height is likely to depend on grass types and densities. Further research is required to confirm this.

In this study, a tripod-mounted single-return laser scanner was considered. There are also other types of laser scanning techniques. One of them is the mobile laser scanning where a laser scanner is often mounted on a ground-based moving platform. As this technique may feature shorter acquisition distances and/or higher incidence angles (compared to the tripod-mounted), laser beams may reach a lower vegetation depth. Another one is the full-waveform laser scanning where the scanner records and processes the entire waveform of a return pulse. This may allow users to extract the information that can be used to derive data points closest to the bare ground. It would be interesting to investigate how the vegetation effect would manifest itself if these laser scanning techniques are used.

\section{Conclusions}

In a TLS survey, the elevation error due to ground vegetation is affected by a variety of parameters, principally the vegetation height and density, scan distance, scan resolution and incidence angle. Edge effects can lead to a smaller vegetation error by recording a scan point lying somewhere between the first surface encountered and a more distant surface. For the fine-resolution scan considered in this study, the vegetation error was about $65 \%$ of the grass height for a $60 \mathrm{~mm}$ by $60 \mathrm{~mm}$ filter window. A larger search window could further reduce the vegetation error by selecting lower points, but topographical detail would be lost.

A fine-resolution scan can reduce vegetation error but is less so for dense grass. Using lower incidence angles (greater visibility) can also reduce vegetation error, as will scanning the same area from multiple locations.

For detecting deformations, vegetation errors in data from sequential surveys will cancel out to some extent, especially for the multi-temporal datasets acquired from the same multiple locations and 
with the same scan parameters. These errors, and the ways in which they can be minimised, must be taken into account when using TLS surveying in an attempt to detect ground movements.

\section{Acknowledgements}

The authors would like to acknowledge funding for the project from the UK Engineering and Physical Sciences Research Council (EPSRC) under grant number EP/G056102/1.

\section{References}

Axelsson, P.E., 1999. Processing of laser scanner data - algorithms and applications. ISPRS Journal of Photogrammetry and Remote Sensing, 54(2-3), 138 -147.

Axelsson, P.E., 2000. DEM generation from laser scanner data using adaptive TIN models. International Archives of Photogrammetry, Remote Sensing and Spatial Information Sciences, 32 (Part B4/1), 110-117

Boehler, W., Bordas, V., Marbs, A., 2003. Investigating Laser Scanner Accuracy XXXIV, Part 5/C15, 696-701.

Buckley, S.J., Howell, J.A., Enge, H.D. and Kurz, T.H., 2008. Terrestrial laser scanning in geology: data acquisition, processing and accuracy considerations. Journal of the Geological Society, 165(3), 625-638.

Centeno, J.A.S., Wutke, J.D. Mitishita, E.A. and Vögtle, T., 2010. Two methods to estimate the spot size of terrestrial laser scanners. Journal of Surveying Engineering, 136(3), 126-131.

Coveney, S. and Fotheringham, A.S., 2011. Terrestrial laser scan error in the presence of dense ground vegetation. The Photogrammetric Record 26(135), 307-324.

Day, S.S., Gran, K.B., Belmont, P. and Wawrzyniec, T., 2013. Measuring bluff erosion part 1: terrestrial laser scanning methods for change detection. Earth Surf. Process. Landforms, 38: $1055-1067$.

Errington, A. F. C., Daku, B.L. F. and Prugger, A.F., 2011. A model based approach to intensity normalization for terrestrial laser scanners. International Symposium on Lidar and Radar Mapping 2011: Technologies and Applications, edited by Xiufeng $\mathrm{He}$, Jia Xu, Vagner G. Ferreira, Proc. of SPIE, vol. 8286, article id. 828605.

Gallay, M., Lloyd, C.D., McKinley, J. and Barry, L., 2013. Assessing modern ground survey methods and airborne laser scanning for digital terrain modelling: A case study from the Lake District, England. Computers \& Geosciences, 51, 216-227.

Guarnieri, A., Vettore, A., Pirotti, F., Menenti, M. and Marani, M., 2009. Retrieval of small-relief marsh morphology from Terrestrial Laser Scanner, optimal spatial filtering, and laser return intensity. Geomorphology, 113, 12-20.

Hall, S. A., Burke, I. C., Box, D. O., Kaufmann, M. R. and Stoker, J. M., 2005. Estimating stand structure using discrete-return lidar: an example from low density, fire prone ponderosa pine forests. Forest Ecology and Management, 208(1-3), 189-209.

Hodgson, M.E. and Bresnahan, P., 2004. Accuracy of airborne lidar-derived elevation: empirical assessment and error budget. Photogrammetric Engineering and Remote sensing, 70(3), 331340.

Hopkinson, C., Chasmer, L.E., Sass, G., Creed, I.F., Sitar, M., Kalbfleisch, W. and Treitz, P., 2005. Vegetation class dependent errors in lidar ground elevation and canopy height estimates in a boreal wetland environment. Canadian Journal of Remote Sensing, 31(2), 191-206.

Hofle, B. and Pfeifer, N., 2007. Correction of laser scanning intensity data: data and model-driven approaches. ISPRS Journal of Photogrammetry and Remote Sensing, 62(6), 415-433. 
Jutzi, B. and Gross, H., 2009. Normalization of LiDAR intensity data based on range and surface incidence angle. Proceedings of ISPRS Workshop: Laser scanning, 213-218, ISPRS.

Kaasalainen, S., Ahokas, E., Hyyppä, J., and Suomalainen, J., 2005. Study of surface brightness from backscattered laser intensity: calibration of laser data. IEEE Geoscience and Remote Sensing Letters, 2(3), 255-259.

Kaasalainen, S., Krooks, A., Kukko, A. and Kaartinen, H. 2009. Radiometric calibration of terrestrial laser scanners with - external reference targets. Remote Sensors, 1(3), 144-158.

Kraus, K. and Pfeifer, N., 1998. Determination of terrain models in wooded areas with airborne laser scanner data. ISPRS Journal of Photogrammetry and Remote Sensing, 53(4), 193-203.

Latypov, D., 2002. Estimating relative lidar accuracy information from overlapping flight lines. ISPRS Journal of Photogrammetry \& Remote Sensing, 56 (4), 236-245.

Leica Geosystems, 2012a. Leica ScanStation C10/C5 system field manual, Version 5.0., Leica Geosystems AG, Switzerland.

Leica Geosystems, 2012b. Leica ScanStation C10 Product Specifications [online], Leica Geosystems AG,Switzerland. http://www.leicageosystems.co.uk/downloads123/hds/hds/ScanStation\%20C10/brochuresdatasheet/Leica_ScanStation_C10_DS_en.pdf [Accessed 16 Oct 2013]

Lichti, D., Gordon, S., and Tipdecho, T., 2005. Error models and propagation in directly georeferenced terrestrial laser scanner networks. Journal of Surveying Engineering, 131(4), $135-142$.

Lim, K., Treitz, P., Wulder, M., St-Onge, B. and Flood, M., 2003. LiDAR remote sensing of forest structure. Progress in Physical Geography, 27(1), 88-106.

Nield, J.M., Wiggs, G.F.S. and Squirrell, R.S., 2011. Aeolian sand strip mobility and protodune development on a drying beach: examining surface moisture and surface roughness patterns measured by terrestrial laser scanning. Earth Surface Processes and Landforms, 36(4), 513522.

Pfeifer, N., Stadler, P. and Briese C., 2001. Derivation of digital terrain models in the SCOP++ environment. OEEPE Workshop on Airborne Laser Scanning and Interferometric SAR for Digital Elevation Models, Stockholm.

Pfeifer, N., Gorte, B. and Vosselman, G., 2003. Laser altimetry and vegetation. Technical Report AGI-GAP-2003-56, Adviesdienst Geo-Informatie en ICT, Rijkswaterstaat, The Netherlands.

Pfeifer, N., Gorte, B. and Elberink., E.O., 2004. Influences of vegetation on laser altimetry - analysis and correction approaches. In International Archives of Photogrammetry and Remote Sensing, Vol. XXXVI, 8/W2, Freiburg, Germany.

Pfeifer, N., Dorninger, P., Haring, A. and Fan, H., 2007. Investigating terrestrial laser scanning intensity data: quality and functional relations. In Proceedings of VIII conference on Optical 3D measurement techniques, ETH Zurich, Switzerland, 328-337.

Pirotti, F., Guarnieri, A. and Vettore, A., 2013. Ground filtering and vegetation mapping using multireturn terrestrial laser scanning. ISPRS Journal of Photogrammetry and Remote Sensing, 76, 56-63.

Schürch, P., Densmore, A.L., Rosser, N.J., Lim, M. and McArdell, B.W., 2011. Detection of surface change in complex topography using terrestrial laser scanning: application to the Illgraben debris-flow channel. Earth Surface Processes and Landforms, 36(14), 1847-1859.

Sibson, R.,1981. A brief description of natural neighbour interpolation (Chapter 2). In V. Barnett. Interpreting Multivariate Data. Chichester: John Wiley.

Soudarissanane, S., Lindenbergh, R., Menenti, M. and Teunissen P., 2011. Scanning geometry: Influencing factor on the quality of terrestrial laser scanning points. ISPRS Journal of Photogrammetry and Remote Sensing, 66(4), 389-399. 
Tang, P., Akinci, B. and Huber, D., 2009. Quantification of edge loss of laser scanned data at spatial discontinuities. Automation in Construction, 18, 1070-1083

Töyrä, J., Pietroniro, A., Hopkinson, C. and Kalbfleisch, W., 2003. Assessment of airborne scanning laser altimetry (LiDAR) in a deltaic wetland environment. Canadian Journal of Remote Sensing, 29(6), 679-690.

Vezočnik, R., Ambrožič, T., Sterle, O., Bilban, G., Pfeifer, N. and Stopar, B., 2009. Use of terrestrial laser scanning technology for long term high precision deformation monitoring. Sensors 9, 9873-9895.

Wang, C., Menenti, M., Stoll, M., Feola, A., Belluco, E., Marani, M., 2009. Separation of ground and low vegetation signatures in LiDAR measurements of salt marsh environments. IEEE Transactions on Geoscience and Remote Sensing, 47 (7), 2014-2023.

Webster, T. L., Forbes, D. L., MacKinnon, E. and Roberts, D., 2006. Flood-risk mapping for stormsurge events and sea-level rise using lidar for southeast New Brunswick. Canadian Journal of Remote Sensing, 32(2), 194-211. 


\section{Figure captions:}

Fig. 1: (a) Site layout (not to scale); (b) vegetation features.

Fig. 2: (a) The S1L1 and S1H1 point clouds; (b) bare ground points.

Fig. 3: (a) Two white plates separated by a distance of $15 \mathrm{~mm}$; (b) the resulting point cloud.

Fig. 4: Edge effects for larger separations (shown at different scales for different separations).

Fig. 5: The bare ground surface.

Fig. 6: The vegetation surface, vegetation height and error.

Fig. 7: (a) The S1H1point cloud; (b) the post-filtering point cloud (local lowest points) using a $60 \mathrm{~mm}$ by $60 \mathrm{~mm}$ search window; (c) the lower bound for the vegetation surface created from the local lowest points using natural neighbour interpolation.

Fig. 8: (a) Vegetation height; (b) vegetation error (both derived from the S1H1 point cloud).

Fig. 9: (a) The relation between vegetation height and error shown in Fig. 8; (b) the variation of the vegetation error with the scan distance for grass of similar height $(0.135 \mathrm{~m}-0.15 \mathrm{~m})$.

Fig. 10: Elevation differences between the lower bounds for the vegetation surface between: (a) repeat fine-resolution scans (S1H1-S1H2); (b) repeat coarse-resolution scans (S1L1 - S1L2), acquired under the same scan conditions.

Fig. 11: Difference in the lower bound of vegetation surfaces for coarse- and fine-resolution scans (S1L1-S1H1).

Fig. 12: Difference in lower bound for vegetation surfaces for fine-resolution scans from different scan stations (S1H1-S2H). 


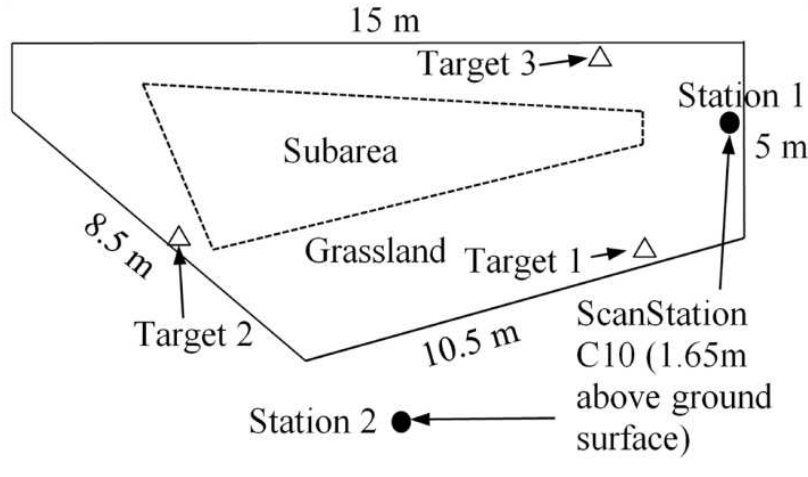

(a)

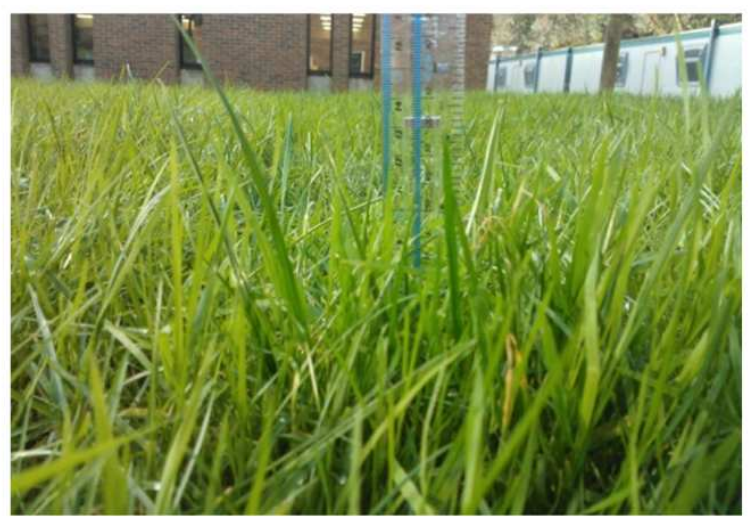

(b)

Fig. 13: (a) Site layout (not to scale); (b) vegetation features. 


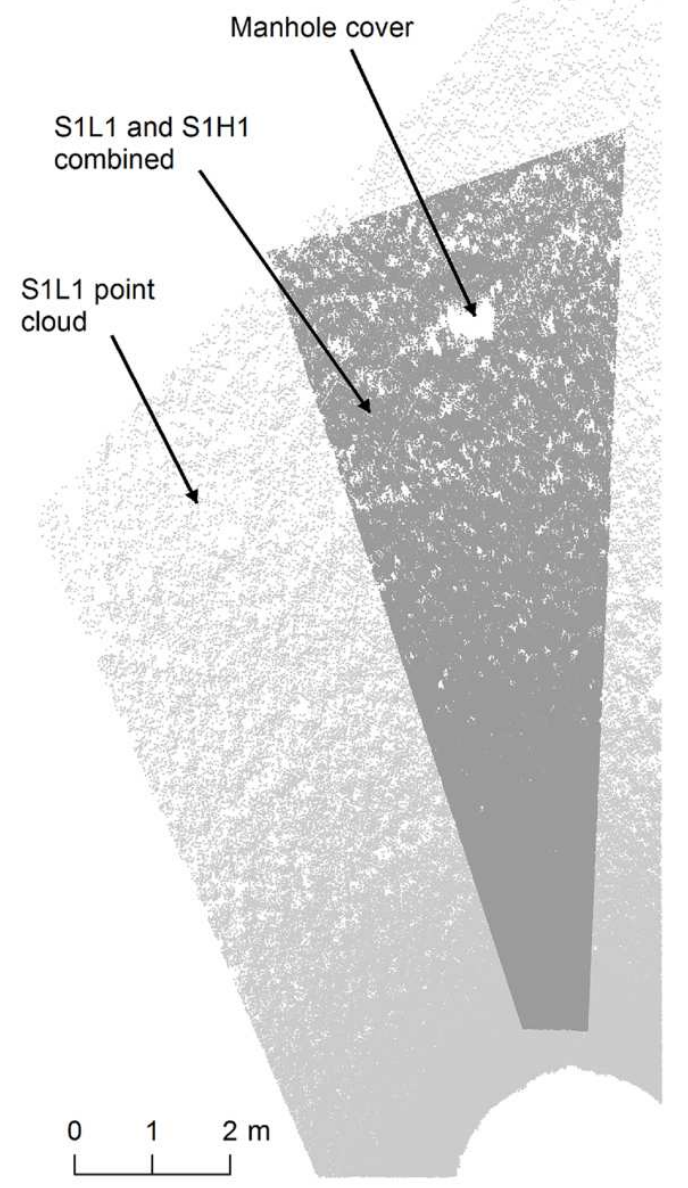

(a)

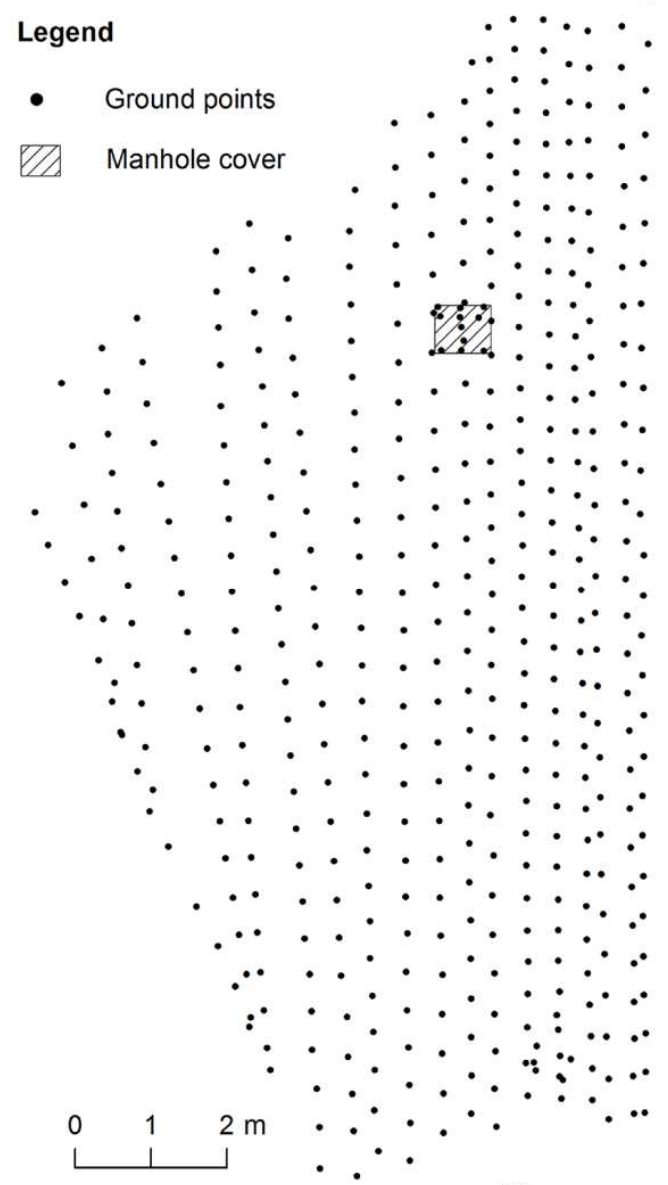

(b)

Fig. 14: (a) The S1L1 and S1H1 point clouds; (b) bare ground points. 

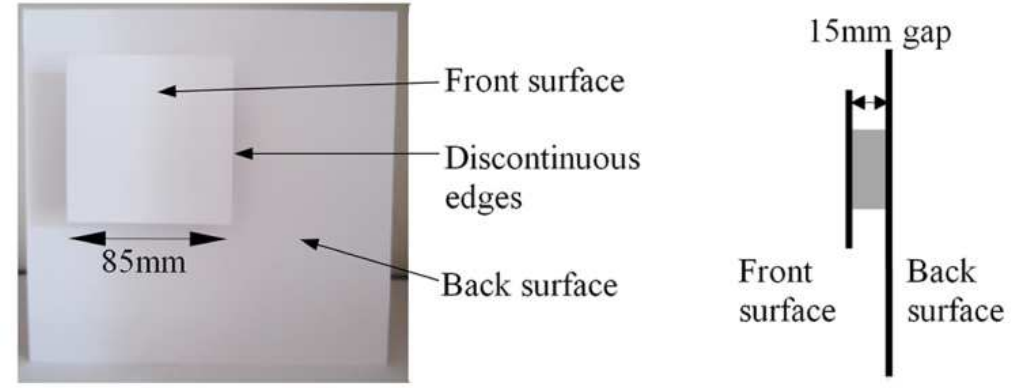

(a)

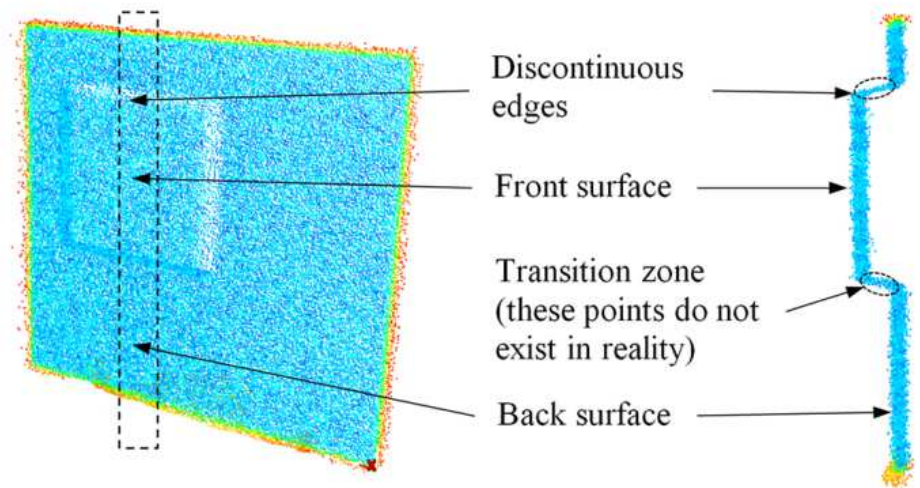

(b)

Fig. 15: (a) Two white plates separated by a distance of $15 \mathrm{~mm}$; (b) the resulting point cloud. 


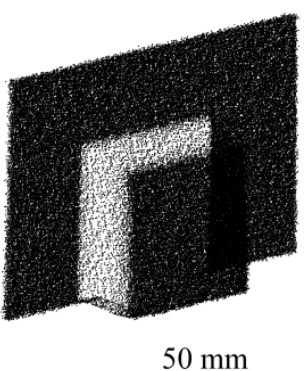

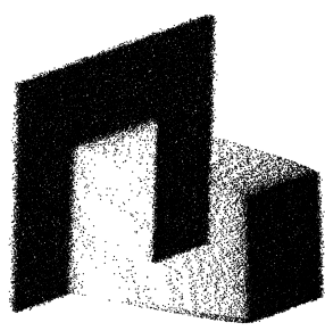

$150 \mathrm{~mm}$

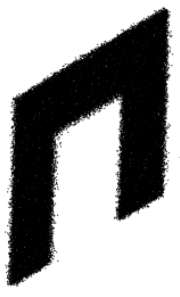

$250 \mathrm{~mm}$
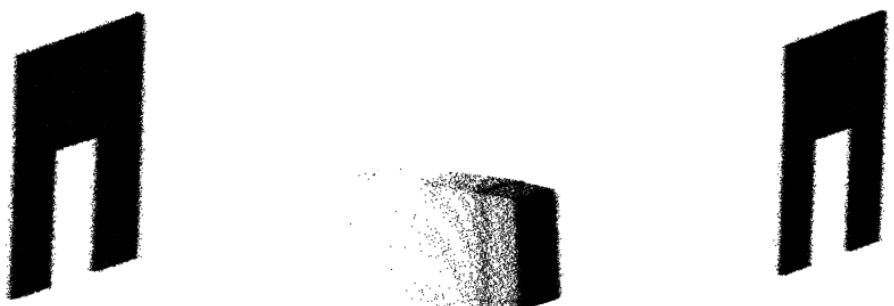

$400 \mathrm{~mm}$
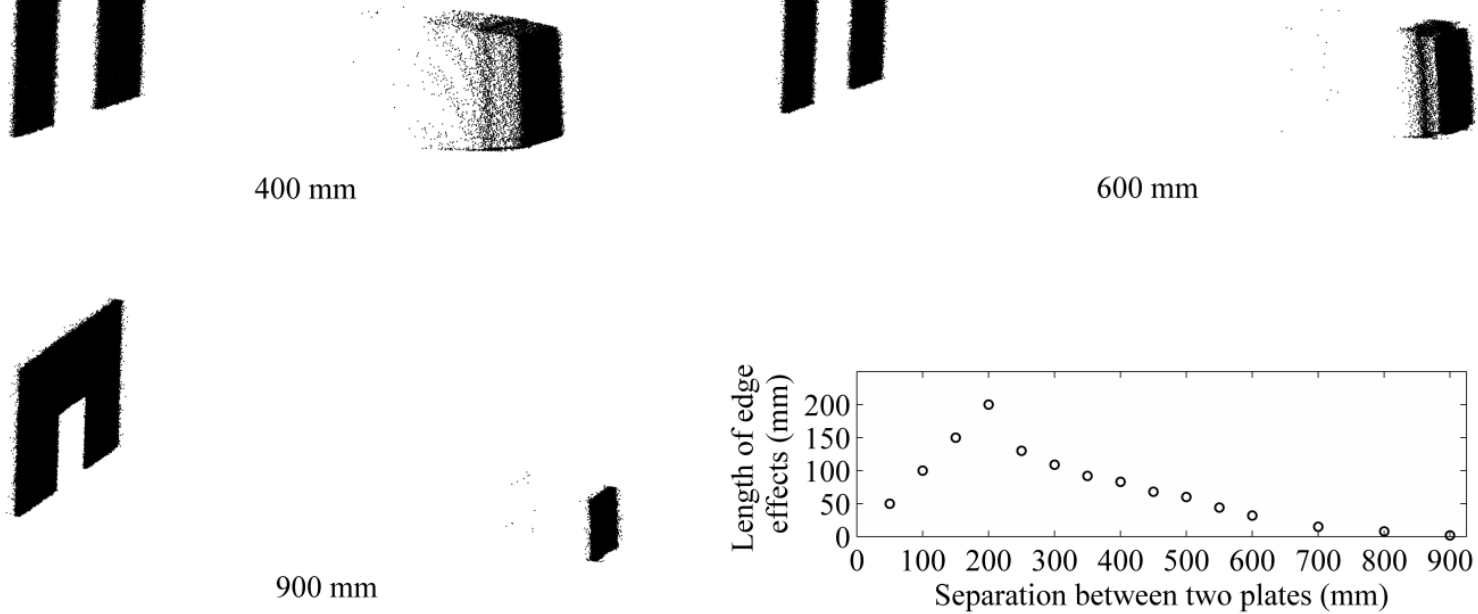

Fig. 16: Edge effects for larger separations (shown at different scales for different separations). 


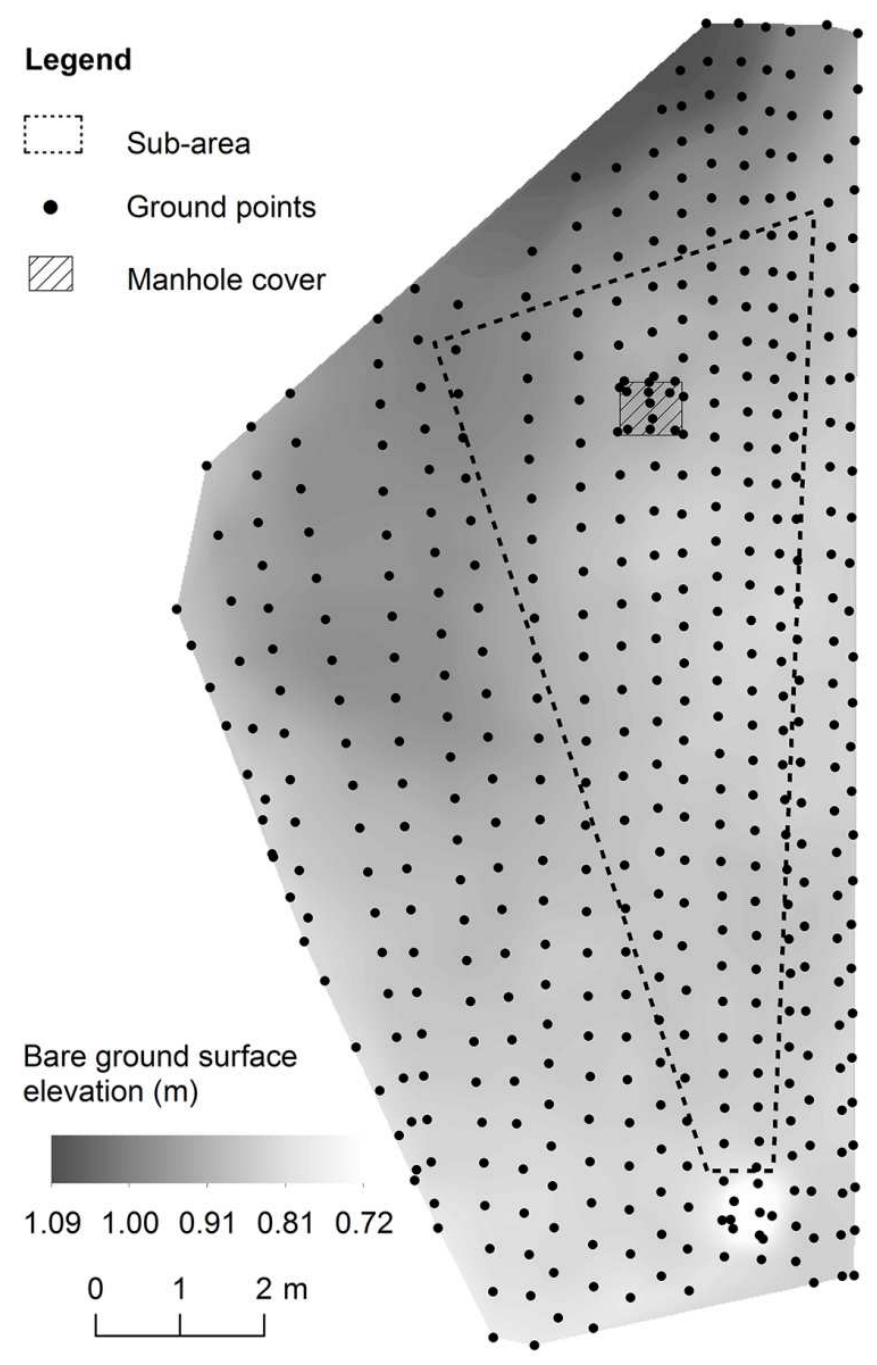

Fig. 17: The bare ground surface. 


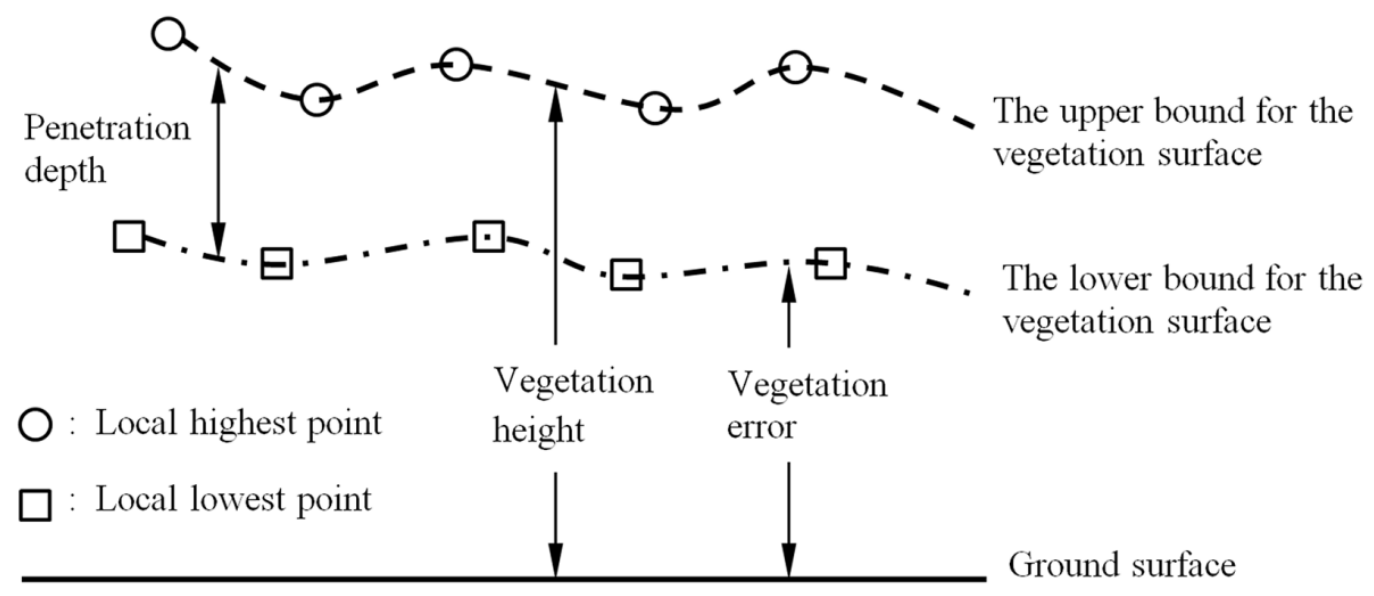

Fig. 18: The vegetation surface, vegetation height and error. 


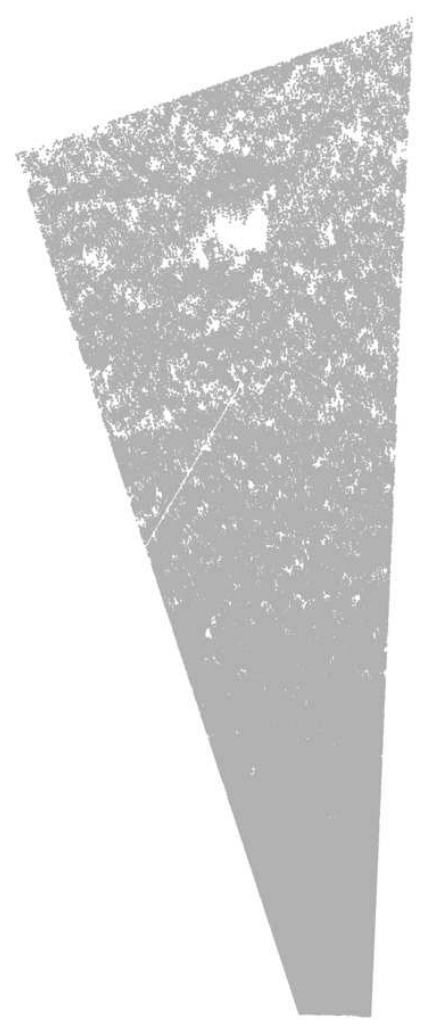

(a)

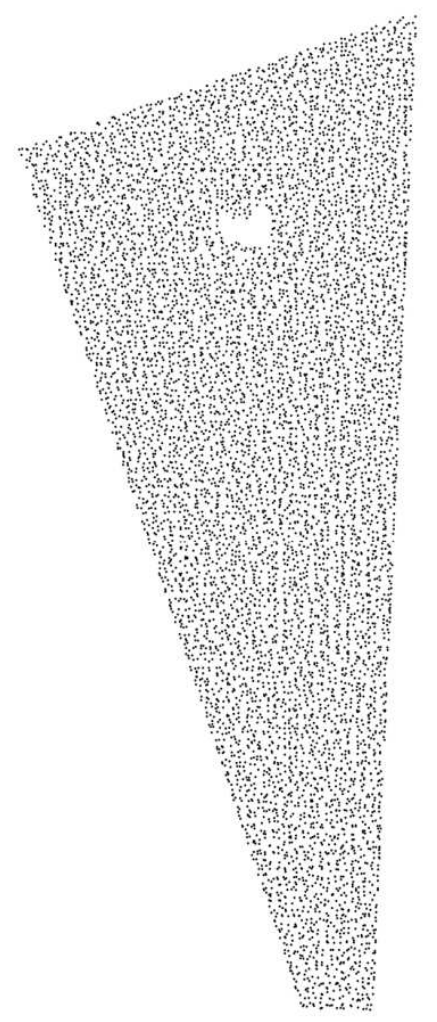

(b)

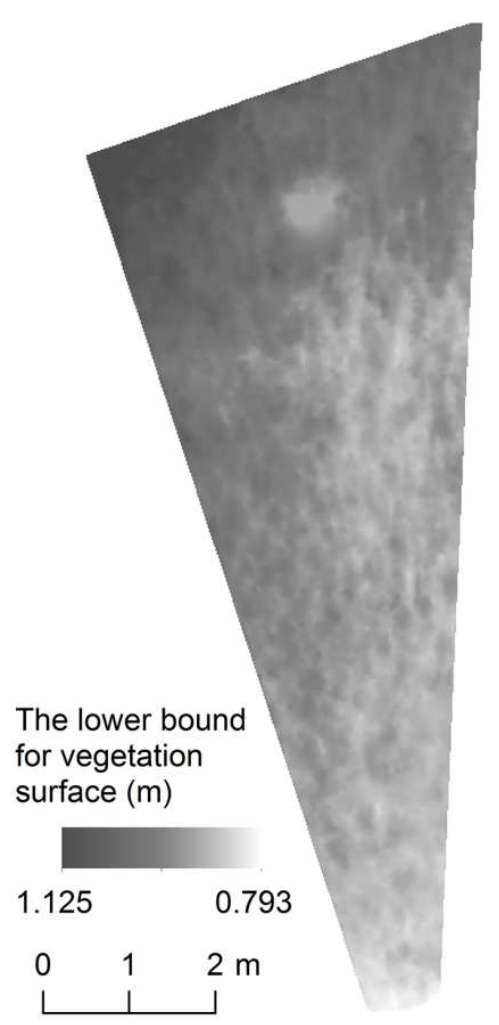

(c)

Fig. 19: (a) The S1H1 point cloud; (b) the post-filtering point cloud (local lowest points) using a 60 $\mathrm{mm}$ by $60 \mathrm{~mm}$ search window; (c) the lower bound for the vegetation surface created from the local lowest points using natural neighbour interpolation. 


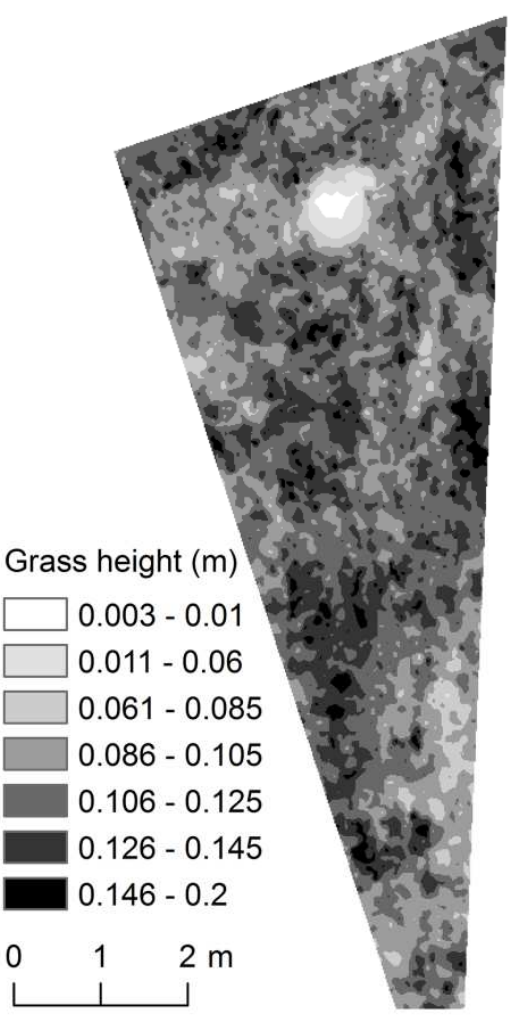

(a)

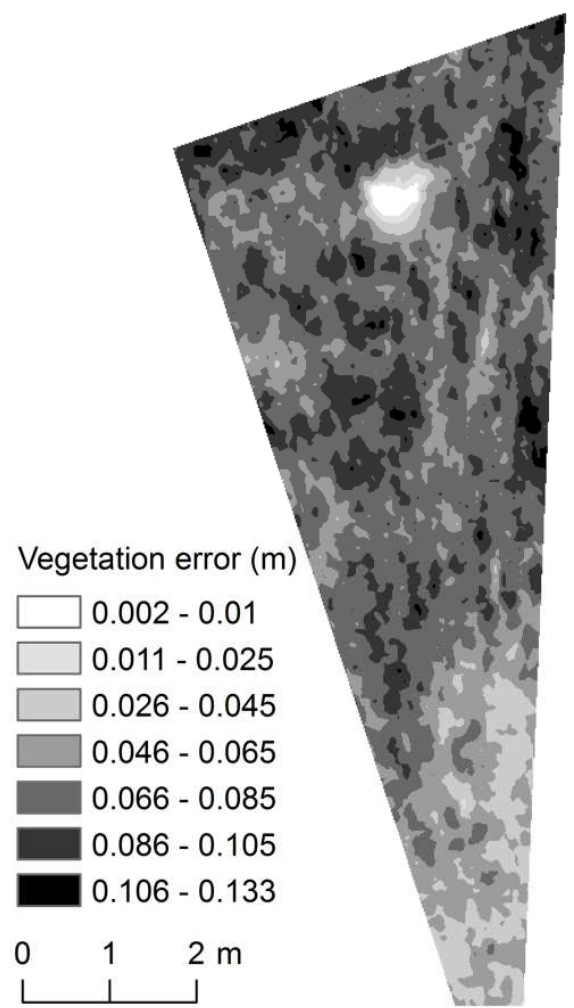

(b)

Fig. 20: (a) Vegetation height; (b) vegetation error (both derived from the S1H1 point cloud). 


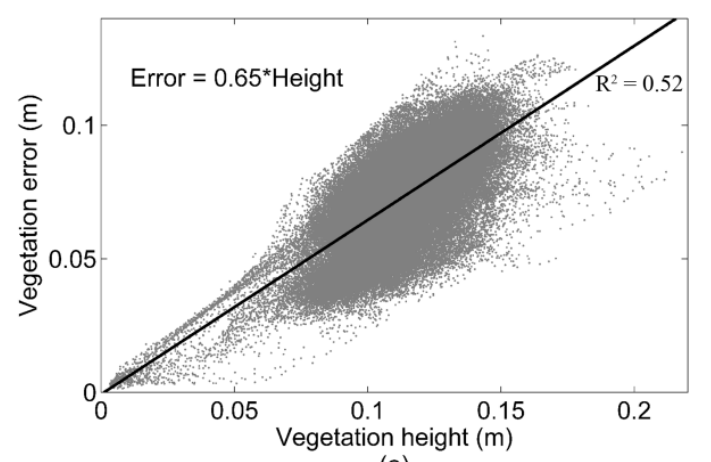

(a)

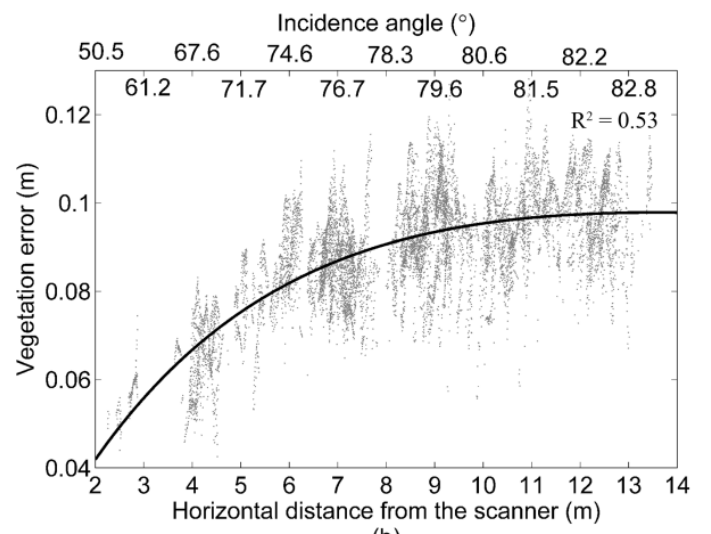

(b)

Fig. 21: (a) The relation between vegetation height and error shown in Fig. 8; (b) the variation of the vegetation error with the scan distance for grass of similar height $(0.135 \mathrm{~m}-0.15 \mathrm{~m})$. 


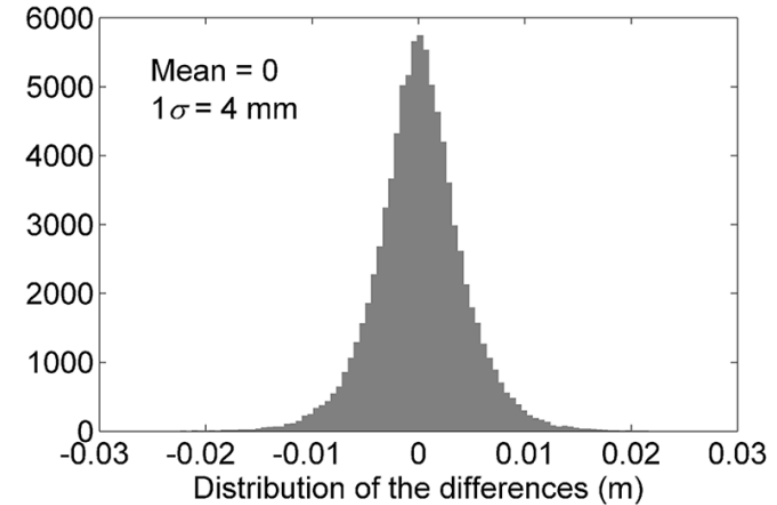

(a)

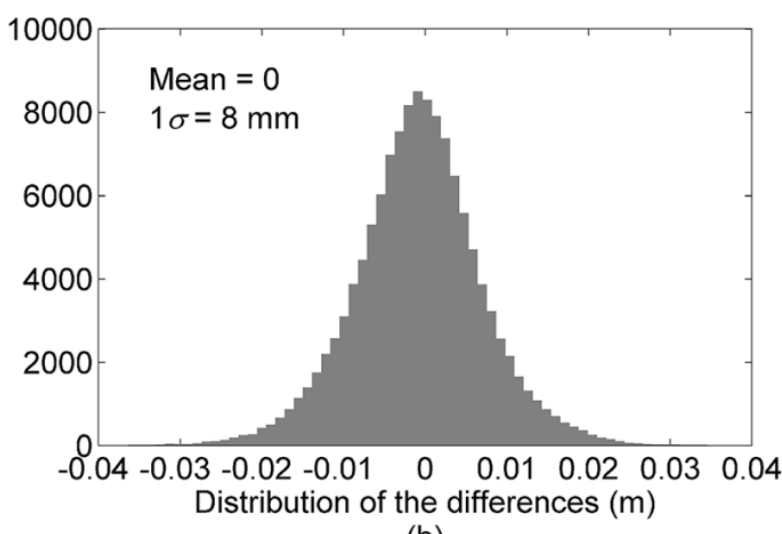

(b)

Fig. 22: Elevation differences between the lower bounds for the vegetation surface between: (a) repeat fine-resolution scans (S1H1-S1H2); (b) repeat coarse-resolution scans (S1L1 - S1L2), acquired under the same scan conditions. 

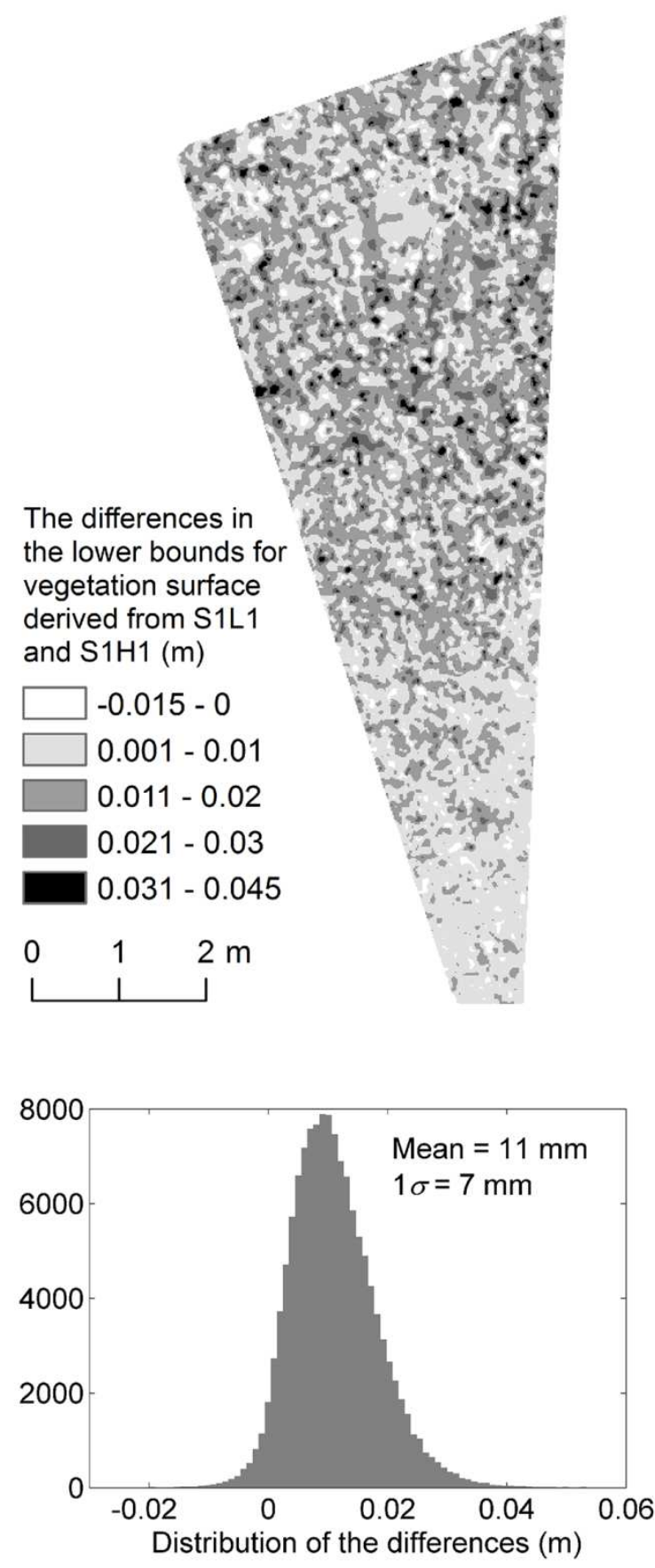

Fig. 23: Difference in the lower bound of vegetation surfaces for coarse- and fine-resolution scans (S1L1-S1H1). 

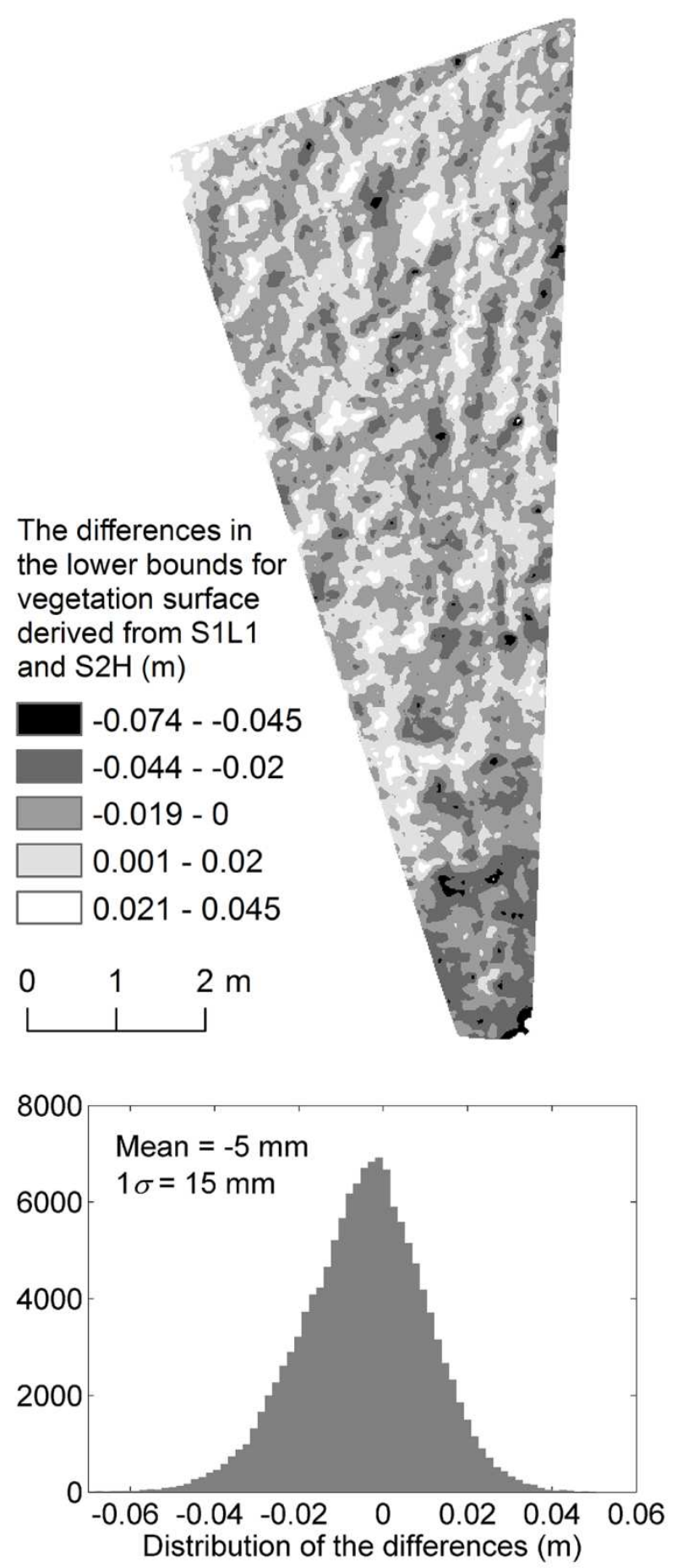

Fig. 24: Difference in lower bound for vegetation surfaces for fine-resolution scans from different scan stations (S1H1-S2H). 